This is an electronic reprint of the original article. This reprint may differ from the original in pagination and typographic detail.

Author(s): Honkasilta, Juho; Vehmas, Simo; Vehkakoski, Tanja

Title: Self-pathologizing, self-condemning, self-liberating: Youths' accounts of their ADHDrelated behavior

Year: $\quad 2016$

Version:

Please cite the original version:

Honkasilta, J., Vehmas, S., \& Vehkakoski, T. (2016). Self-pathologizing, self-

condemning, self-liberating: Youths' accounts of their ADHD-related behavior. Social Science and Medicine, 150(February), 248-255.

https://doi.org/10.1016/j.socscimed.2015.12.030

All material supplied via JYX is protected by copyright and other intellectual property rights, and duplication or sale of all or part of any of the repository collections is not permitted, except that material may be duplicated by you for your research use or educational purposes in electronic or print form. You must obtain permission for any other use. Electronic or print copies may not be offered, whether for sale or otherwise to anyone who is not an authorised user. 


\title{
Self-pathologizing, self-condemning, self-liberating: Youths' accounts of their ADHD-related behavior
}

\begin{abstract}
This study analyzes the discursive construction of attention deficit hyperactivity disorder (ADHD) and self in relation to a socioculturally shared understanding of moral norms. Thirteen Finnish youth aged 11 to 16 diagnosed with ADHD were interviewed during this discourse analysis study. The youth accounted for their culturally undesirable behavior, performance and traits through three different types of accounts: (1) externalizing personal responsibility due to a compelling medical condition, (2) internalizing personal responsibility through moral self-condemnation, and (3) distancing oneself from the socially imposed stereotypes and stigmas related to ADHD. This study challenges dominant understanding of young people with a diagnosis of ADHD and contributes to our understanding of how ADHD is constructed in their lives.
\end{abstract}

Keywords: Finland, attention deficit hyperactivity disorder (ADHD), account, discourse analysis, youth, moral responsibility, identity, interview

\section{Introduction}

Attention deficit hyperactivity disorder (ADHD), a neurodevelopmental disorder manifesting core symptoms of inattentiveness, impulsiveness, and hyperactivity, is one of the most common and contested mental disorders diagnosed among young people (for an outline of the debate, see Barkley et al., 2002 and Timimi et al., 2004). Unwanted behavior and performance associated with ADHD is explained by the psychomedical model that ADHD can affect individuals across their lifespan in different spheres of life (education, social life, etc.) due to complex genetic (e.g., genes regulating neurotransmitter systems) and 
neurobiological (e.g., dopamine dysregulation) anomalies hindering self-regulation abilities (e.g., Mueller \& Tomblin, 2012; Tarver, Daley, \& Sayal, 2014).

As for these possible adverse trajectories and failure to meet the criteria of "good", "well-behaved" citizens in contemporary society, the diagnosis of ADHD serves many functions. At the individual level, ADHD offers a legitimate "scapegoat", especially in vernacular use, to absolve the individual (pupil, guardian, teacher) from responsibility for troublesome conduct by locating the problem within brain activity (e.g., Bailey, 2014; Harwood, 2006; Schubert et al, 2009; Singh, 2011) - a child is viewed as a passive sufferer of a compulsive medical condition that subdues agency and moral responsibility. Simultaneously, ADHD label is laden with the promise of becoming socially understood, accepted, and supported (Emerald \& Carpenter, 2010). Thus, social practices dominantly directed by the psychomedical discourse not only maintain the psychopathology of certain cognitive and behavioral traits that could be educationally intervened but also harness such psychopathology as means of moral normalization.

Thus far, the meaning of ADHD in the accounts of youth is still not fully understood. The internalization of discourses regarding ADHD is related to expert explanations youth are given (Brady, 2005). When complex social and educational problems are reduced to a psychomedical deficit by using the language of disorder and dysfunction, one may internalize problems as solely based in the individual (Graham, 2007; Harwood, 2006). In the light of our data it can be plausibly argued that the psychomedical discourse is oversimplifying and insufficient in furthering our understanding of what it means to "live with ADHD". As Gee (2000-2001) has argued, when a child receives a diagnosis, caregivers and physicians have already recognized ADHD as the child's nature-identity, a state developed due to natural forces, and as the child's institution-identity, a position authorized by legitimate institutions and professionals. Along with the diagnosis, the child is exposed to various discourses of which the psychomedical model dominates (Danforth \& Navarro, 2001; Norris \& Lloyd, 2000). The question now becomes what kinds of discourse-identities (i.e., being recognized as a certain "kind of" person in authentic interaction situations) are made available to those diagnosed, other than "ADHD child/student" (Gee, 2000-2001). However, existing empirical research has drawn little 
attention to this idea. In this article, the discursive construction of ADHD and of self in relation to ADHD is analyzed in how thirteen diagnosed Finnish youth account for their behavior associated with ADHD.

\section{Previous empirical research on young people's perspective on ADHD}

The literature voicing children and youth diagnosed with ADHD has emphasized their experiences and perceptions of the disorder and self in relation to it. Young people are reported to associate ADHD with social and educational difficulties (e.g., Cooper \& Shea, 1998; Kendall, Hatton, Becket, \& Leo, 2003; Krueger \& Kendall, 2001; Singh, 2011). Further, they have been found to view medication as valuable as it increases the ability to self-manage behavior and improves academic performance (Cooper \& Shea, 1998; Kendall et al., 2003; Loe \& Cuttino, 2008; Singh, 2013b; Singh et al., 2010). These findings suggest that children and youth perceive the authentic self as fundamentally bad, problematic, or incapable, and welcome medication as an empowering, normalizing and enabling factor (Singh, 2013a, 2013b; Loe \& Cuttino, 2008).

However, above constructs of ADHD and selves do not testify to individual deficit outright. Instead, they testify to dominant deterministic discourses that social and behavioral issues associated to ADHD are reducible to individual biology (Cooper $\&$ Shea, 1998; Travell $\&$ Visser, 2007). Contrary to these discourses, young people are reported to attribute the severity of manifestation, and even the existence of the problems associated with ADHD, to environmental factors, especially teacher and peer conduct (e.g., Cooper \& Shea, 1998; Gallichan \& Curle, 2008), emphasizing the importance of classroom interaction over the diagnosis and its supposed value (Prosser, 2008). In addition, children and youth have reported downsides related to medical treatment, varying from unwanted side effects to the changes medication causes in one's authentic self (Cooper \& Shea, 1998; Loe \& Cuttino, 2008). As for the label, youth are aware of and concerned about the stigma of the label and their conduct (e.g., Cooper \& Shea, 1998; Singh et al., 2010). Various studies have emphasized that children and youth view themselves as if something were fundamentally wrong in them (e.g., Brady, 2014; Cooper \& Shea, 1998; Kendall et al., 2003; Singh, 2007; Travell \& Visser, 2007), a view the label promotes due to children perceiving themselves as defective 
(Brady, 2005). Further, Krueger and Kendall (2001, p. 61) concluded that "an ADHD adolescent's sense of self is distorted" due to integrating one's identity with the disorder: "They were their ADHD and their ADHD was them" (p. 64). Alternatively, other researchers have proposed that children/youth "neither fully accept nor fully reject the medical definition of their experience but actively work to redefine the experience to make it meaningful to them" (Brady, 2014, pp. 225-226; Gajaria, Yeung, Goodale, \& Charach, 2011; Prosser, 2008).

The diverse findings call into question the simplistic perspective that reduces young people's behavior or performance regarded as symptomatic as derived solely from neurological dysfunction or impairment in cognitive processing. Kendall and colleagues (2003), Singh (2011), and Singh and colleagues (2010) reported young people accounting for their intentional fighting as a valid, justifiable, and unavoidable act within the youth microculture (e.g., as a badge of honor). This finding is important because adults may interpret transgression in terms of diagnostic symptomology (e.g., impulsiveness). Similarly, youth may exploit the ADHD label as a scapegoat to excuse their actions (Kendall et al., 2003; Singh, 2011; Singh et al., 2010). Singh $(2011,2013 a)$ pointed out that, among youth studied in the United Kingdom, the modal method of viewing ADHD was to associate it with bad conduct and that exploiting the label was common, whereas in the United States ADHD was associated with bad academic performance with a tendency to keep the label secret. Different (youth) cultures and cultural factors (race, socioeconomics, etc.) socialize individuals into varying norms of contextually valued beings. When students fail to fit in, it illustrates not only student traits but also the characteristics of their social environment (Gallichan \& Curle, 2008)-its values, norms, and practices. These practices not only regulate one's conduct but also, at worst, emphasize an individual's powerlessness to do nothing but submit to the prevailing unfortunate social surroundings (e.g., bullying, stigma). This was demonstrated by Exley (2008), who gave children labeled as having ADHD instructions to create an imaginary story about what would happen to a puppy that exhibited ADHD-like behavior at school. Despite the opportunity to use their imagination, the children's experiences and sociocultural associations of ADHD directed their stories toward deficit discourse that victimized the individual - the puppy was forewarned to stay in class, in its haven. 


\section{Study frame}

This study included thirteen Finnish youth, aged 11 to 16, diagnosed with ADHD. The study focused on the accounts the youth spontaneously provided in interviews of narrated behavior, performance and traits they related to ADHD. An account, in the tradition of linguistic discourse analysis, is conceptualized as a discursive practice that individuals use to view themselves as culturally acceptable in relation to others and social norms (e.g., Edwards \& Potter, 1992; Garfinkel, 1967). The accounts protect the self-image from valuative questioning about a supposedly undesirable act (Scott \& Lyman, 1968; Sterponi, 2003) and are used in face-to-face interviews to negotiate (self-)acceptance along with a socioculturally shared understanding of moral norms and ADHD.

The discursive construction of ADHD and selves has yet drawn scant attention in previous literature voicing young people so-labeled. This study addresses this dearth of literature. Studying account giving in interview interaction allows us to study ADHD as a discursive entity and, thus, as a sociocultural construct. This paper is based on a discourse analytic understanding of youth as active meaning makers, who, while expressing personal experiences construct selves by drawing on cultural representations and discourses familiar to Western societies that afford and occlude certain moral opportunities and responsibilities (Danforth \& Navarro, 2001; Norris \& Lloyd, 2000). We treat language as a gateway to cultural values, norms, and expectations the narrator acknowledges and in relation to which constructs, deconstructs, or reconstructs his or her own social identities. Our aim is not to discredit the validity of experienced problems or the importance of taking such experiences into account in providing healthcare and education. Instead, we argue that studying the cultural constructs in young people's accounts is important to gain a comprehensive understanding of the meanings assigned to ADHD as a biopsychological and sociocultural phenomenon. Our research questions were as follows: (1) How do youth diagnosed with ADHD account for the ways of behaving, performing, and being they relate negatively to ADHD? (2) What kinds of preconditions of moral responsibility do these accounts meet? 


\section{Method}

\section{Data}

The participants were recruited through the Finnish ADHD Association by sending information letters (one for parents, one for children) to member families about the opportunity to participate in research focusing on the experiences of parents and their children diagnosed with ADHD regarding the child's compulsory schooling. The family participation required that the child was (1) formally diagnosed, (2) aged 11-16, and (3) willing to participate. This recruitment approach was to ensure participants' familiarity with discourses surrounding ADHD. Thirteen families with two girls and 11 boys diagnosed with ADHD participated (mean age 13.7, mean age at diagnosis 8.3). Parents' background information is summarized in Table 1. Participant assent was confirmed verbally and in writing from young participants and their parents. Ethical approval for research from the University of Jyväskylä Ethical Committee was obtained.

Table 1. Parents' information

\begin{tabular}{|c|c|c|c|c|c|c|c|c|c|c|c|c|}
\hline \multicolumn{4}{|c|}{ Parents' level of education (\%) } & \multicolumn{2}{|c|}{$\begin{array}{c}\text { Parents' } \\
\text { employment } \\
\text { situation }(n)\end{array}$} & \multicolumn{4}{|c|}{ Family type (n) } & \multicolumn{3}{|c|}{$\begin{array}{c}\text { Self-reported } \\
\text { activity in the ADHD } \\
\text { Association }(n)\end{array}$} \\
\hline $\begin{array}{l}\text { Bas } \\
\text { ic }\end{array}$ & $\begin{array}{l}\text { Vocatio } \\
\text { nal }\end{array}$ & $\begin{array}{l}\text { Colle } \\
\text { ge }\end{array}$ & $\begin{array}{l}\text { Univer } \\
\text { sity }\end{array}$ & $\begin{array}{l}\text { Emplo } \\
\text { yed }\end{array}$ & $\begin{array}{l}\text { Unemplo } \\
\text { yed }\end{array}$ & $\begin{array}{l}\text { Nucl } \\
\text { ear } \\
\text { famil } \\
\text { y }\end{array}$ & $\begin{array}{l}\text { Blend } \\
\text { ed } \\
\text { famil } \\
y\end{array}$ & $\begin{array}{l}\text { Divorc } \\
\text { ed }\end{array}$ & $\begin{array}{l}\text { Singl } \\
\text { e } \\
\text { pare } \\
\text { nt }\end{array}$ & $\begin{array}{l}\text { Activ } \\
\text { e }\end{array}$ & Little & $\begin{array}{l}\text { Non } \\
- \\
\text { acti } \\
\text { ve }\end{array}$ \\
\hline 8 & 44 & 20 & 28 & 24 & 1 & 10 & 1 & 1 & 1 & $\begin{array}{l}1 \\
\text { mot } \\
\text { her }\end{array}$ & $\begin{array}{l}4 \\
\text { moth } \\
\text { ers }\end{array}$ & 20 \\
\hline \multicolumn{4}{|c|}{ Total $100 \%$} & \multicolumn{2}{|c|}{ Total 25 parents } & \multicolumn{4}{|c|}{ Total 13 families } & \multicolumn{3}{|c|}{ Total 25 parents } \\
\hline
\end{tabular}

The interviews were mainly conducted in the participants' homes in a setting the youth chose; however, three interviews were conducted on the university premises due to the parents' wishes. Two interviews were conducted in conjunction with the parent discussion, one because a boy eventually declined to participate alone and the other because a girl took the initiative to participate during her parents' interview. The audio-recorded interviews lasted on average, for around 90 minutes. 
The broad semi-structured interview topics covered the participants' representations of school, own school attendance, teachers, and ADHD. The interviews were conducted by using the free association narrative interview method (Hollway \& J efferson, 2008). Also, feeling cards with a wide range of positively, neutrally, and negatively charged feelings (happy, bewildered, frustrated, etc.) were used with assignments regarding perception of self and teachers. The cards were not considered in the analysis; the sole purpose of the interview methods were to enable free, intuitive meaning making followed by open narrative questions by the interviewer (e.g., "earlier you mentioned...could you tell me more about it?"). The use of interview methods was negotiated with the participants, and in two cases, functional methods were omitted because the participants expressed their comfort and confidence in talking without any auxiliary means.

The interview questions and methods were not directed to elicit accounts; the participants provided accounts of their own behavior related to ADHD spontaneously without prompting by the interviewer. Thus, we assume that they were important ways in which the youth constructed their identities in the interview and are a legitimate focus (see Cooper \& Shea, 1998).

\section{Data analysis}

The analysis of the accounts of youth was based on the linguistic discourse analysis tradition, which highlights the action orientation and functionality of language and the dynamics of language use and cultural meaning making. We focused on the ways particular sociocultural norms and identities were contextually naturalized in interaction. We started the analysis by coding only the utterances that the youth themselves explicitly associated with ADHD-related behavior or that were co-constructed with the interviewer (direct questions about ADHD). After this coding phase, applying the tradition of discursive psychology (Edwards \& Potter, 1992) inspired by conversation analysis (Heritage, 2001), we focused on how utterances about self and own behavior were given, for which purpose, and under which sociocultural circumstances, by analyzing form (word choices, passive/ active voice, the use of modalities, or other syntactic structures) and function (meaning or the communicative purpose a form carries out) (Gee, 2004). 
When categorizing the utterances in relation to their functions we also applied Scott and Lyman's (1968) division of accounts (excuses and justifications) and our conceptual contribution (moral self-disclosure).

Qualitative interview as a means of data collection has been debated within the discursive social-scientific field due to its researcher-provoked nature (for an outline, see Nikander, 2012). Eliciting spontaneous reactions responds to this critique. Further, our analysis regards interviews as a collaborative production of talk in interaction and both parties as active agents and agenda setters (Nikander, 2012).

The trustworthiness of this study can be assessed from various aspects. First, the possibility of biased interpretations was diminished through systematic coding of the grammatical and contextual features of the utterances. This also contributed to the controllability and, if possible, non-judgmentality of the analysis (Wetherell, 2001). Second, the conformability of the analysis was strengthened due to collaboration between researchers during the analysis process, enabling cross-reading and constant comparison of the data analysis within the methodological and theoretical frames of discourse analysis (Bogdan \& Biklen, 2006). Third, the assessment of credibility of the study is made possible for the reader through authentic data examples with detailed analysis and reasoning presented in the Results section. Last, the results are transferrable because the accounts cannot be reduced solely to the level of the individual mind but are representations of culturally and socially shared and upheld discourses (Hammersley, 2003).

The extracts were translated into English with the assistance of a language consultant with an emphasis on idiomatic translation and replicating the original verbatim records as exactly as possible. All names used in the article are pseudonyms. The following transcription symbols are used: (.) micro-pause; (1.0) pause measured in seconds; (-)/ (--) one/two or more words missing; [JH: Ok] short overlapping utterances of participants inserted in ongoing talk; ((ADHD)) author's clarification; hh laughter; (" ") reported speech within transcription quote. 


\section{Results: Accounting for "normality"}

Socially undesirable behavior youth explicitly associated with ADHD, mainly described as various everyday troubles instead of misconduct harmful to other people, was narrated in three types of accounts: 1) excuses by externalizing personal responsibility, 2) moral self-disclosures by assuming mainly retrospective responsibility through self-condemnation, or 3) justifications by resisting constructed social stigmas and recategorizing the self in relation to them. As summarized in Table 2, these accounts of the constructed consequences of ADHD for the narrators' behavior and agency during the interview varied. The first two accounts concern the ways of making narrated behavior understandable in terms of socially acceptable behavior. In these accounts, the ADHD medical model is reproduced as a priori premise for constructing self; however, the degrees of control over the condition and of desirability of adhering to the psychomedical discourse vary. The third account challenges the normative criteria of and the psychomedical discourse on ADHD-related behavior and the self.

Table 2. Young people's accounts of their ADHD-related behavior

\begin{tabular}{|l|l|l|l|l|}
\hline Account & Self-statement & $\begin{array}{l}\text { ADHD-related } \\
\text { behavior }\end{array}$ & $\begin{array}{l}\text { Self- } \\
\text { positioning }\end{array}$ & $\begin{array}{l}\text { Accounting } \\
\text { mechanism }\end{array}$ \\
\hline Excuses & $\begin{array}{l}\text { "I have been diagnosed } \\
\text { with ADHD, and I } \\
\text { should be accepted as I } \\
\text { am based on the } \\
\text { informed knowledge of } \\
\text { my impaired condition } \\
\text { caused by ADHD" }\end{array}$ & $\begin{array}{l}\text { Negative and } \\
\text { uncontrollable }\end{array}$ & Victim & Self-pathologizing \\
\hline Moral self- \\
disclosures & $\begin{array}{l}\text { "I have been diagnosed } \\
\text { with ADHD, but I } \\
\text { should be accepted as I } \\
\text { am for I acknowledge } \\
\text { the inappropriateness } \\
\text { of my past behavior } \\
\text { and can, or strive to, } \\
\text { control it" }\end{array}$ & $\begin{array}{l}\text { Negative but } \\
\text { controllable or to be } \\
\text { controlled }\end{array}$ & Moral agent & Self-condemning \\
Justifications & $\begin{array}{l}\text { "I have been diagnosed } \\
\text { neverth ADH; } \\
\text { be accepted as I am, } \\
\text { for, behind the label } \\
\text { and my personal traits, }\end{array}$ & $\begin{array}{l}\text { Neutral and } \\
\text { authentic way of } \\
\text { being }\end{array}$ & Self-advocate & Self-liberating \\
\hline
\end{tabular}




\begin{tabular}{|l|l|l|l|l|}
\hline & $\begin{array}{l}\text { I am an individual - a } \\
\text { human being" }\end{array}$ & & & \\
\hline
\end{tabular}

\section{Excuses: Externalizing personal responsibility}

When moral responsibility and agency are dissipated through excuses (see Scott \& Lyman, 1968), youth approach ADHD-related behavior from a medical viewpoint and reduce their behavior to an uncontrollable compulsive biological trait. ADHD is positioned as an agent that overrules the individual's agency: "((ADHD is)) a sort of illness in my brain that disturbs my concentration and makes me hyper" (M ichael, 16), and "it sort of somehow stops me from like always having my books with me" (Laura, 15). Thus, acceptability of one's behavior is assured through a psycho-pathologizing process in which ADHD becomes a legitimate scapegoat to absolve the youth from moral responsibility for troublesome conduct by locating the problem within brain activity (e.g., Singh, 2011).

In addition to reducing problem behavior to uncontrollable neurobiological factors, the youth also externalize responsibility in relation to various situational factors that trigger or prevent undesirable behavior (e.g., Gallichan \& Curle, 2008). Participants describe their inability to perform in terms of whether the classroom environment was favorable for socially expected behavior: "when there was loads of noise, ya couldn't manage to concentrate anymore" (Pete, 16); "when everyone's going manic and that you start going manic yourself" (John, 12). The youth thus externalize conduct and misconduct from personal control ("ya couldn't"; "you start going manic") and rely on others to meet the normative expectations of (classroom) conduct.

In extract 1 , the participant (Pete, 16) attributes evaded responsibility to ADHD, which he constructs as a neurobiological condition. He describes how his fifth- and sixth-grade teacher was "pretty often mad at me about something" and talks about the turning point in his teacher's response.

Extract 1. 
1 Pete: Dunno (2.0) he stopped being at some point (.) my mum gave him, I can't remember if it was to

$6 \mathrm{JH}: \quad$ Right (3.0) in what ways did you notice he'd learned to give a bit more slack?

7 Pete: Well, he sort of (2.0) like understood (.) me a bit better and why I'm just sometimes the way I am

$8 \quad \mathrm{JH}: \quad$ You mean sometimes (.) not doing as you're told?

9 Pete: Yeah (3.0) stuff like that (1.0) and generally being a bit (1.0) sort of like (1.0) being deliberately

In extract 1, Pete uses the ADHD label to excuse his actions: He implies his behavior is not mischievous but can be objectively explained by a medical condition. This appears in Pete's reference to his mother's book, which he associates with a change in his teacher's response. The adverb "actually" in line 3 marks the truth value of the clause (Quirk et al., in Clift, 2001) and shows Pete's commitment to a medicalized explanation for his behavior that otherwise would be labeled annoying and malicious. In an extreme example in lines 911, Pete constructs ADHD as an explanation (and a legitimate excuse) for his behavior. However, the sensitiveness of admitting such conduct becomes evident as Pete's narration falters (Potter, 2004; Schubert et al., 2009). Not until the interviewer suggests, "You mean sometimes not doing as you're told?" does Pete express himself in lines 9-10 more descriptively, yet evasively and with delays. This indicates Pete's awareness of moral rules of conduct and adherence to them; his confession makes him subject to moral condemnation. However, his evasion in externalizing his own responsibility for the conduct shows he is aware of the face-saving function of psychomedical discourse and can mobilize this knowledge. 
The same evasive linguistic features also dominate narrations about medication in which it is constructed as an agent (e.g., "it helps me concentrate more, and it gets rid of the sort of edginess," Thomas, 13). Participants observed medication aids responsible performance otherwise diminished by the neurological condition. In extract 2, Jack (14) describes his reluctance to omit medication even at weekends because of negative consequences, such as not "getting anything done."

\section{Extract 2}

$1 \mathrm{JH}: \quad$ Could you (.) sort of explain a bit (.) what you mean by that?

2 Jack: You don't (.) so like if you've simply got to empty the dishwasher or something (2.0) you don't always (.) normally (.) well even normally it takes ages 'cause you don't feel like it (1.5) [JH: hh] or even if you do feel like it it doesn't (.) you can't (.) you just can't do it 'cause (1.5) you feel all massively full of energy and you've got to kick off and jump about 'n stuff

This extract highlights the conviction that ADHD symptoms cannot be controlled. Jack uses the dynamic modal verb form "can" with negative polarization along with the subordinating conjunction "even if" in line 4 to convince that it is not a question of a lack of his moral will but of the impossibility of self-control. He constructs medication as normalizing the self and, resonating with Singh $(2007,2013 b)$, prefers his "medicated self" to "his authentic self." By distancing himself from being an active agent in the narration through generic voice, Jack evades taking personal responsibility for perceived difficulties and, more importantly, explicates them as well-known symptoms experienced by all people diagnosed with ADHD.

A morally responsible agent is typically capable 1) of evaluating one's reasons for acting and 2) of acting of one's own free will (Fischer \& Ravizza, 1998, p. 13). In this account, the youth do not report their issues as outcomes of ignorance but are aware of their behavior and the norms and expectations surrounding the behavior. However, their strong commitment to psychomedical discourse characterized by causal attributions between ADHD and difficulties in meeting the normative social expectations suggest that they do not regard themselves as being completely in control because in their experience their condition 
subdues free will. Thus, using excuses for ADHD-related behavior seems to ensure the accountability of behavior that would be questioned; the medical condition liberates actors, at least partly, from moral responsibility. By using excuses, the youth reproduce the psychomedical discourse and accept the identity of "ADHD youth" struggling with control over their "disordered bodies" (see also Loe \& Cuttino, 2008).

\section{Moral self-disclosure: Assuming distanced responsibility}

In this account of moral self-disclosure, the youth portray themselves as morally virtuous through selfcondemnation, highlighting their current understanding of, and commitment to, existing moral norms. Unlike in the previous account, in this account, the youth construct the self as self-assertive and responsible and, thus, having control over "disordered bodies" (see Cooper \& Shea, 1998; Loe \& Cuttino, 2008). Accountability is ensured through mainly chronologically distanced moral self-pathologization by which one strives to be seen as a mature individual who acknowledges and commits to the existing norms. The youth orient toward psychological growth, self-reflection, and self-governance instead of purely medical interventions by emphasizing their personal development as an individual. Thus, the participants' current situation differs from the previous by reassuring they have their symptoms under control (e.g. "I can behave the same and be just the same even if I'm (.) even if I like haven't taken the medication," Jacob, 11). The use of active first person singular and the dynamic modal verb "can" emphasizes strong agency regarding self-control.

In extract 3, the interviewer had asked whether M arcus (15) had concerns regarding school. As a response, M arcus reports how he had transformed himself from "a bad student to a good student" and thanked his social worker. He further elicited as follows.

\section{Extract 3}

$1 \quad$ Marcus: $\quad$ Me and mum are maybe a bit (.) too different seeing as we've anyhow been (--) pretty much always together just the two of us, and I'm a bit worried about my mum, too, 'cause I in a 

way I haven't been the easiest of kids [J H: M m] and I've caused quite a lot of trouble with having had (-) having ADHD and it's been a massive hassle with behavior

$(--)$

$5 \mathrm{JH}:$ Um (.) you (.) said a moment back (1.5) that it sort of (1.0) hasn't been easy for your mum either with you having had ADHD [M arcus: M m](.) what did you mean by that (.) could you explain that a bit?

Marcus: Well, it's definitely (.) loads of times I've been (.) seriously tough (.) and like then when there've been bad reports from day care or school [jH: M m] then for mum it's sort of been like (.) it can't be easy to like have to go (.) 'cause "your son has done this and that"

In this extract, Marcus' narration about the negative consequences of his behavioral traits for his mother foregrounds his moral self-disclosure. The change in tenses is interesting. Marcus's use of the present tense when he expresses empathy with his mother in line 2 due to educational and social distress he "ha[s] caused" fortifies his moral self-reflection concerning his ADHD-related behavior. Further, the discursive device "it can't be easy" in line 10 attaches $M$ arcus to the generally shared normative criterion of "an easy child"-a position he has failed to meet. These explicit self-disclosures highlighted by negative extreme depictions (e.g., "it's definitely (.) loads of times I've been (.) seriously tough") frame the moral, critically self-evaluating nature of his account. However, these bona fide concessions and the change of the tense from present to perfect with a reference to past normalizes $M$ arcus in the present interaction (see Antaki \& Wetherell, 1999). That is, M arcus displays his knowledge of and commitment to morally desirable behavior and being; although he constructs ADHD as a medical disorder that backgrounds his behavior and the mother's distress, he eschews use of it as an excuse. Conversely, M arcus positions himself as an agent of the narration through the use of active first person singular forms and assumes responsibility for his actions. In other words, the medical model of ADHD may shape behavior, but the label does not need to define how the self is recognized (e.g., Brady, 2014; Gajaria et al., 2011). 
The same agency construction is also in extract 4. Dave (12) constructs his conduct related to ADHD as controllable or at least disguisable in the classroom. Earlier, Dave had mentioned that his concentration might wander during class.

\section{Extract 4}

$1 \quad \mathrm{JH}: \quad$ So what helps you (.) if your concentration starts wandering somewhere else?

2 Dave: I start fiddling with my pencil and eraser or swinging my feet (2.0) or then I (.) sometimes I've thrown my eraser (.) on the floor on purpose (.) or dropped my pencil (.) and then gone to get it (.) so I get to move about [JH: Right ok] I go and have a drink (.) even though I'm not thirsty

Although the interviewer gives the noun "concentration" in an agentive form in line 1, Dave does not adopt similar evasive linguistic formations (cf., excuses) but assumes responsibility for his actions by using the active first person singular form. This is interesting, because the classroom conduct Dave constructs as intentional is associated with disruptive behavior and is regarded as a manifestation of symptoms of motor restlessness and inattention. However, Dave turns this psychopathological assumption upside down as he chooses to fiddle, throw and drop a pencil, and so on in order to improve his behavior. Similarly, Dave reveals a dissonance between psychomedical and normative discourses: his performance is not constrained by his neurobiology but by normative classroom practices which do not normally permit his actions ("so I get to move about"). Instead of excusing his actions with ADHD, Dave performs morally responsible agency by describing intentional use of self-learned compensational methods and highlights his informed knowledge of how to control his condition in order to blend into prevailing norms.

In this accounting, ADHD symptoms are referred to as an objective fact, but the participants position themselves as rational agents who know right from wrong and who have the capacity to make free choices. Thus, contrary to excuses, they construct themselves as praiseworthy or blameworthy for their actions (Fischer \& Ravizza, 1998). Attributions to ADHD are constructed to contradict normative ideals of behavior 
and being. These ideals are embodied through moral condemnation of this "deviant condition." Thus, consequently, the protection of the self is evident. The narrators use the agentive single first person pronoun only when they judge their own ADHD-related characteristics or explain them as absent or under control; they construct ADHD as something to be controlled. Adherence to normative moral discourse by being aware of norms and sensitive to the consequences of one's own actions is a face-saving device in interpersonal interaction.

\section{Justification: Negotiating with social stigma}

The third account is justification of one's individuality, an objection to stereotypical deviancy imposed on those labeled. Thus, although the youth accept responsibility for the socially questionable act, they seek to "deny the pejorative quality associated with it" (Scott \& Lyman, 1968, p. 47). They problematize homogeneous expectations by re-categorizing the problematic behavior and rejecting psychomedical pathologization and the related social stigma. In extract 5, Susan (16) had earlier mentioned being mistreated at school because she was in a special education class; the interviewer asked for clarification.

\section{Extract 5}

1 Susan: $\quad$ Yeah I mean I've never (1.0) at all felt like I belong there ((special education classroom)) I've always known I'm totally normal [JH: Mm] (.) I've just got (1.0) a few small problems (1.0) with self-control and stuff like that (1.0) same as (1.0) the same (.) basically same as someone being shy [JH: M m] all I am is just like the opposite [JH: Ok] (.) to that (2.0) so just like (1.5) like whereas another person might be shy I'm just that kind of person that I dare to just say to anyone (2.0) anything I want to say or like I dared to (.) because I don't basically (2.0) now if I say something then I do think for a sec what I'm gonna say

Susan downplays the symptoms she relates to ADHD by mitigating them as "small problems with selfcontrol" (see also the adverb "just" in lines 2, 4-6), by explicitly normalizing herself (line 2), and by juxtaposing the symptoms with shyness (lines 3-4). In doing so, she breaks down the alleged symptoms 
into permanent personal traits-virtues even ("I dare to")—-and detaches herself from the ADHD category. Thus, the "problematic conduct" characteristic of ADHD symptomatology becomes re-categorized as a socially constructed anomaly; certain personal characteristics lead to being controlled by institutional rules and regulations whereas other traits like shyness do not. However, Susan defuses her strong stance at the end of the extract: "or like I dared to (--) now if I say something then I do think for a sec what I'm gonna say". Although her justification is legitimate, she acknowledges moral responsibility for her (re)actions.

The youth also evade potential stigma due to ADHD through counter (self-)narratives, in which one justifies one's authenticity by deconstructing culturally stereotypical associations. In extract 6, Laura (15) is asked how ADHD is regarded at school.

\section{Extract 6}

1 Laura: Well, 'cause other kids at school don't know what it ((ADHD)) is they think they're totally mad and got problems 'n stuff but they're actually not like that

$3 \mathrm{JH}: \quad$ What are they like?

4 Laura: They're really like just a normal person who with some things gets (1.0) difficulties (3.0) with certain (1.0) things like l've got with math

$6 \mathrm{JH}: \quad$ In what sort of way do you feel that these other pupils should (.) kind of (1.0) understand more?

8 Laura: If they perhaps knew more (1.0) then they wouldn't like judge straight away (1.0) coz hardly any of them have ever seen a case like this before so they'd like sort of know a bit about it (1.0) 'cause like some of my friends I told at first thought I was joking them 
Laura's account resonates with Goffman's (1963) work on negotiating between virtual and actual social identity. She attempts to avoid social stigma by concealing and normalizing her ADHD identity. The rhetorical use of friends as reliable witnesses (line 10) ratifies her withdrawal from the ADHD category. She deconstructs the imposed ADHD stigma by de-emphasizing her manifestation of the stereotypical behavior of those so-labeled. However, this withdrawal is not trouble-free. Despite the active dissociation attempts, Laura identifies with the stigma by referring to herself as "a case like this" (line 9) and, by so doing, claims a position in the ADHD category. As no manifest symptoms are constructed, the label defines her vague, unwanted, and imposed membership. Further, since absolute emancipation is constructed as unfeasible, she strives to normalize and humanize the people like her (lines 2-4). She uses the coordinating conjunction "but" and the discursive devices "actually" and "really" to contradict the stereotypical expectations for people diagnosed with ADHD and emphasize the factuality of the humane characteristics of these individuals (Clift, 2001; Schubert et al., 2009). However, while normalizing so-called ADHD people, Laura simultaneously distances herself from "the[m]" by using the same linguistic means introduced when excuses are given (evasiveness, faltering delivery). ADHD and related behavior are thus constructed as a priori stigmatized in the interview.

Justifications present the whole ADHD phenomenon in a different light than the two previous accounts. The moral evaluative part of this account is more society- than self-oriented. Instead of making the individual accountable in relation to dominant ideals of behaving and being, justifications provide insight into questioning the taken-for-granted nature of the social order and re-examining the norms and values it advocates. The youth admit to not meeting the norm, yet they do not accept it as a basis for being perceived accountable. In terms of responsibility, justifications for one's own way of behaving and being act as a self-liberating counter-argument against expectations to take moral responsibility for something that is imposed and that the youth have difficulty relating to. This account derives from an inclusive discourse and advocates for an individual's unique existence (see Graham, 2007; Harwood, 2006). 


\section{Discussion}

This paper analyzed how youth diagnosed with ADHD provided accounts of their ADHD-related behavior, performance, and traits. The youth used three types of accounts to narrate potentially undesirable behavior and to produce moral responsibility or disengage from it: excuses, moral self-disclosures, and justifications.

ADHD constructed through excuses resonated with Schubert and colleagues' (2009) findings. ADHD was constructed as a factual, morally neutral medical category which set boundaries on and determined young people's potential actions. Adhering to the psychomedical discourse assured accountability for one's behavior because the self was not constructed as an agent with free will but as an actor performing neurogoverned actions. Simultaneously, and conversely, in the accounts of moral self-disclosure and justifications, medical explanations did not absolve the individual from moral responsibility; instead, the participants claimed they possessed free will over their condition and aimed at being perceived as responsible agents (see also Kendall et al., 2003). Then, the youth differentiated themselves from the ADHD category for one of two reasons: (a) to emphasize one's character as morally responsible by reproducing extant norms of good behavior and reducing the undesirable behavior to one's past immaturity (moral selfdisclosures) or (b) to normalize one's character by freeing the self from false, stereotypical, and stigmatizing images of ADHD (justifications). In contrast to the first two accounts, justifications emphasized how norms and other people within the moral community constricted the participants' freedom of choice and possibilities for self-actualization (see Gajaria et al., 2011). This account was a counter-speech against regulatory discourses-a self-liberating ethos that made behavior and ways of being accountable.

This study makes an important contribution to discussions about social mechanisms related to psychiatric classifications. Hacking (1995) famously argued that psychiatric diagnoses may produce a looping effect of human kinds. The looping effect refers to a process where "people classified in a certain way tend to conform to or grow into the ways that they are described; but they also evolve in their own ways, so that the classifications and descriptions have to be constantly revised" (p. 21). In this light, adaptation to "living 
with ADHD" entails a socialization process, through which young people learn to accept and utilize new self-definitions and simultaneously withdraw from the social consequences of being so labeled. Contrary to Krueger and Kendall (2001), who found that adolescents integrate their identity with the disorder, our analysis suggested that youth accepted "having" ADHD-they found ways to mobilize the psychomedical discourse to their own advantage in being recognized as a certain "kind of person" (see also Brady, 2014; Prosser, 2008; Singh, 2011). However, they did not identify as "being" ADHD. Conversely, the results revealed the conflicting construction of ADHD: It was simultaneously a medical disorder absolving the participants of responsibility and a socially imposed, a priori stigma that defined a narrator's deviancy in interviews. In other words, although ADHD seemed to be used as a legitimate account for transgression of norms, interpreting one's own behavior or traits through it also called for accountability. Research like this focusing on the discursive practices of those classified into a certain diagnostic category beyond the psychomedical interpretative frame is essential. If the experience of young people not fitting in the diagnostic category gains widespread acceptance, it might highlight the need to revise the classification, or at the very least the social practices built around it.

The results question the uncritical use of psychomedical interpretative frames in professional practice such as in explaining school behaviors of youth diagnosed with ADHD or planning educational interventions for them (see also Bailey, 2014; Harwood, 2006; Whitt \& Danforth, 2010). First, the dominant, reductionist essentialist meaning making promoted by psychomedical discourse disregards the meaningfulness and desirability of such explanations in young people's lives; as a medical entity, ADHD was simultaneously constructed as uncontrollable, controllable, and to be controlled, whereas as an identity label, ADHD exempted the youth from moral questioning while simultaneously posing a threat of being perceived as morally questionable. Second, the dominant approach disregards the complexity of social interaction. Instead of passively accepting ADHD as an imposed, unequivocal characteristic, the youth actively engaged with the label and weighed what it meant in their lives with varying meanings given to ADHD and effects on moral selves (see also Brady, 2014; Prosser 2008). 


\section{Conclusions}

This study challenges dominant understanding of young people with a diagnosis of ADHD and contributes to our understanding of how ADHD is constructed in their lives. The dominant cultural discourses available to laypersons draw from psychomedical domains, posing moral problems of child behavior as individual phenomena subject to diagnosis and medical interventions (Danforth \& Navarro, 2001; Norris \& Lloyd, 2000). This study complements previous research on how the psychomedical discourse of ADHD is deployed in everyday school practices (e.g., Bailey, 2014; Hjörne, 2006) by demonstrating the insufficiency of the discourse for understanding the youth experiences of "Iiving with ADHD", let alone undesirability. The youth intentionally constructed their selves in relation to ADHD, and vice versa, in the vortex of discourses internalized by them providing deeply embedded varying and contradictive cultural meanings for ADHD. Giving accounts reproduces unquestioned cultural values and reflects and shapes available social identities. To change the potentially harmful identity constructions, the inclusive, not the psychomedical, discourse should be mobilized in everyday educational practices to emancipate individuals from experiencing difficulties due to cultural (self-)blame.

Being limited to interview interactions, this study lacks valuable information about how this culture of blame attains its fundamental legitimacy in interaction in everyday educational social practices (cf., Bailey, 2014; Hjörne, 2006). Further research could usefully explore this through naturally occurring data, such as video observations of classroom interaction.

\section{References}

Antaki, C., \& Wetherell, M. (1999). Show concessions. Discourse Studies, 1(1), 7-27.

Bailey, S. (2014). Exploring ADHD: An ethnography of disorder in early childhood. New York, NY: Routledge. 
Barkley, R. A., Diamond, A., Zametkin, A., Thapar, A., Teeter, A., Anastopoulos, A. . . Pelham, W. (2002). International consensus statement on ADHD. Clinical Child and Family Psychology Review, 5(2), 89111.

Bogdan, R. C., \& Biklen, S. K. (2006). Qualitative research in education: An introduction to theory and methods. Boston, MA: Allyn \& Bacon.

Brady, G. (2005). ADHD, diagnosis and identity. In C. Newnes \& N. Radcliffe (Eds.), M aking and breaking children's lives (pp. 49-59). Ross-on-Wye, England: PCCS Books.

Brady, G. (2014). Children and ADHD: Seeking control within the constraints of diagnosis. Children \& Society, $28,218-230$.

Clift, R. (2001). M eaning in interaction: The case of actually. Linguistic society of America, 77(2), 245-291.

Cooper, P., \& Shea, T. (1998). Pupil's perceptions of AD/HD. Emotional and Behavioural Difficulties, 3, 3648.

Danforth, S., \& Navarro, V. (2001). Hyper talk: Sampling the social construction of ADHD in everyday language. Anthropology and Education Quarterly, 32(2), 167-190.

Edwards, D., \& Potter, J. (1992). Discursive psychology. London, England: Sage.

Emerald, E. \& Carpenter, L. (2010). ADHD, mothers, and the politics of school recognition. In L. J. Graham (Ed.), (De)Constructing ADHD: Critical guidance for teachers and teacher educators (pp. 99-118). New York, NY: Peter Lang.

Exley, B. (2008). "Staying in class so no one can get to him": A case for the institutional reproduction of ADHD categories and behaviours. International J ournal of Inclusive Education, 12(1), 65-80.

Fischer, J. M ., \& Ravizza, M. (1998). Responsibility and control: A theory of moral responsibility. Cambridge, England: Cambridge University Press.

Gajaria, A., Yeung, E., Goodale, T., \& Charach, A. (2011). Beliefs about attention-deficit/hyperactivity disorder and response to stereotypes: Youth postings in Facebook groups. Journal of Adolescent Health, 49, 15-20. 
Gallichan, D. J., \& Curle, C. (2008). Fitting square pegs into round holes: The challenge of coping with attention-deficit hyperactivity disorder. Clinical Child Psychology and Psychiatry, 13, 343-364.

Garfinkel, H. (1967). Studies in ethnomethodology. Cambridge, England: Polity Press.

Gee, J. P. (2000-2001). Identity as an analytic lens for research in education. Review of Research in Education, 25, 99-125.

Gee, J. P. (2004). Discourse analysis: What makes it critical? In R. Rogers (Ed.), An introduction to critical discourse analysis in education (pp. 19-50). Mahwah, NJ: Erlbaum.

Goffman, E. (1963). Stigma: Notes on the management of soiled identity. New York, NY : Simon \& Schuster.

Graham L. (2007). Speaking of "disorderly" objects: A poetics of pedagogical discourse. Discourse: Studies in the Cultural Politics of Education, 28(1), 1-20.

Hacking, I. (1995). Rewriting the soul: M ultiple personality and the sciences of memory. Princeton, NJ:

Princeton University Press.

Hammersley, M. (2003). Conversation analysis and discourse analysis: methods or paradigms? Discourse \& Society, 14(6), 751-781.

Harwood, V. (2006). Diagnosing 'disorderly' children, London, England: Routledge.

Heritage, J. (2001). Goffman, Garfinkel and conversation analysis. In M. Wetherell, S. Taylor, \& S. J. Yates (Eds.), Discourse theory and practice. A reader (pp. 47-56). London, England: Sage.

Hjörne, E. (2006). Pedagogy in the ADHD classroom: An exploratory study of the Little Group. In G. Lloyd, D. Cohen, \&J. Stead (Eds.), Critical new perspectives on Attention Deficit/Hyperactivity disorder (pp. 176-197). Oxon, England: Routledge Falmer.

Hollway, W., \& Jefferson, T. (2008). The free association narrative interview method. In L. M. Given (Ed.), The Sage encyclopedia of qualitative research methods (pp. 296-315). Thousand Oaks, CA: Sage. Kendall, R. N., Hatton, D., Beckett, A., \& Leo, M. (2003). Children's accounts of attentiondeficit/hyperactivity disorder. Advances in Nursing Science, 26(2), 114-130.

Krueger, M ., \& Kendall, J. (2001). Descriptions of self: An exploratory study of adolescents with ADHD. Journal of Child and Adolescent Psychiatric Nursing, 14(2), 61-72. 
Loe, M., \& Cuttino, L. (2008). Grappling with the medicated self: The case of ADHD college students. Symbolic Interaction, 31(3), 303-323.

M ueller, K. L., \& Tomblin, J. B. (2012). Diagnosis of ADHD and its behavioral, neurologic and genetic roots. Topics in Language Disorders, 32(3), 207-227.

Nikander, P. (2012). Interviews as discourse data. In J. F. Gubrium, J. A. Holstein, A. B. Marvasti, \& K. D. M cKinney (Eds.), The SAGE handbook of interview research: The complexity of the craft (2nd ed.; pp. 397-413). London, England: Sage.

Norris, C., \& Lloyd, G. (2000). Parents, professionals and ADHD - What the papers say. European Journal of Special Needs Education, 15(2), 123-137.

Potter, J. (2004). Representing reality: Discourse, rhetoric and social construction. London, England: Sage.

Prosser, B. J. (2008). Beyond ADHD: A consideration of attention deficit hyperactivity disorder and pedagogy in Australian schools. International Journal of Inclusive Education, 12(1), 81-97.

Scott, M. B., \& Lyman, S. M. (1968). Accounts. American Sociological Review, 33(1), 46-62.

Schubert, S. J., Hansen, S., Dyer, K. R., \& Rapley, M. (2009). "ADHD patient" or "illicit drug user"? M anaging medico-moral membership categories in drug dependence services. Discourse $\&$ Society, 20(4), 499-516.

Singh, I. (2007). Clinical implications of ethical concepts: M oral self-understandings in children taking methylphenidate for ADHD. Clinical Child Psychology and Psychiatry, 12, 167-182.

Singh, I., Kendall, T., Taylor, C., M ears, A., Hollis, C., Batty, M., \& Keenan, S. (2010). Young people's experience of ADHD and stimulant medication: A qualitative study for the NICE guideline. Child and Adolescent M ental Health, 15(4), 186-192.

Singh, I. (2011). A disorder of anger and aggression: Children's perspectives on attention deficit/hyperactivity disorder in the UK. Social Science \& M edicine, 73(6), 889-896.

Singh, I. (2013a). Brain talk: Power and negotiation in children's discourse about self, brain and behaviour. Sociology of Health \& IIIness, 35(6), 813-827. 
Singh, I. (2013b). Not robots: Children's perspectives on authenticity, moral agency and stimulant drug treatments. Journal of Medical Ethics, 39,359-366.

Sterponi, L. (2003). Account episodes in family discourse: The making of morality in everyday interaction. Discourse Studies, 5(1), 79-100.

Tarver, J., Daley, D., \& Sayal, K. (2014). Attention-deficit hyperactivity disorder (ADHD): An updated review of the essential facts. Child: Care, Health and Development, 40(6), 762-774.

Timimi, S., M oncrieff, J., Jureidini, J., Leo, J., Cohen, D., Whitfield, C., .. . White, R. (2004). A critique of the international consensus statement on ADHD. Clinical Child and Family Psychology Review, 7(1), 5963.

Travell, C., \& Visser, J. (2007). "ADHD does bad stuff to you": Young people's and parents' experiences and perceptions of attention deficit hyperactivity disorder (ADHD). Emotional and Behavioural Difficulties, 11(3), 205-216.

Wetherell, M. (2001). Debates in discourse research. In M. Wetherell, S. Taylor, \& S. J. Yates (Eds.), Discourse theory and practice: A reader (pp. 380-399). London, England: Sage.

Whitt, P. B., \& Danforth, S. (2010). Reclaiming the power of address: New metaphors and narrative for challenging behaviors. In L. J. Graham (Ed.), (De)Constructing ADHD: Critical guidance for teachers and teacher educators (pp. 143-164). New York, NY: Lang. 